difficulty is to evolve some method of charging which will apportion to each consumer his proper share of the standing charges. He made a most ingenious suggestion for constructing meters the rates of which would depend on the times of the day at which the consumer would be taking his loads. We foresee that there would be great difficulties in explaining this system of charging to new consumers and serious difficulties with electric motor-clocks, and humming noises would have to be overcome.

ANother suggestion made by Prof. Walker for improving the load factor of our central stations and thus enabling prices to be reduced is to utilise the potential power load of motor-cars and omnibuses for equalising the load. Much has been said about the advantages of making petrol and oil from British coal; but if the problem is to transfer the energy stored in our coal to the axles of our motor-cars, it is very much more efficient to generate electrical energy by means of big turbo sets, store it in batteries, and empty it in electric motors, than it is to convert only a fraction of the coal into petrol and employ that in internal combustion engines. If the distribution of electricity were on a national scale, we should have to dot about the country hundreds of battery stations at distances not greater than ten miles apart. Electric cars could be built taking batteries of a standard size. The driver of the car would only have to stop at a station every 20 miles or so and change his battery. It could be mounted and wheeled about in such a way that the process of changing it would be as easy as filling up with petrol. If it were necessary to have a tax, it could be imposed upon the charged battery. The gain to the State would be millions of pounds per annum, at present paid to foreign countries for petrol. Our central stations would be kept busy during the early hours of the morning in charging the traction batteries. It would lead to increasing the output of our central stations without increasing their capacity. Another help for reducing the price of electricity would be to educate consumers to reduce their bills by keeping down their maximum demands by using a special indicator.

\section{Electrical Equipment of Automobiles}

THE electrical equipment of a motor-car is now an essential portion of the whole vehicle. This is proved in a paper by Mr. E. A. Watson (J. Inst. Elec. Eng., March) describing the progress made during the last three years in the electrical equipment of cars. In the modern car, the driver should never be called upon to resort to hand-starting. The starter handle is carried separately in the tool kit, and in many designs can only be inserted with difficulty, its main function being to turn the engine round for adjusting purposes and not for starting. The ignition now is almost always by electric coil and not by a magneto. To assist the convenience in driving, electric petrol pumps, windscreen wipers and horns are used. Recently the remarkable progress made in the combined textile and rubber driving-belt has led to a reversion to the belt-driven dynamo. These are entirely satisfactory and have a normal life of 20,000 miles or more. This drive possesses the advantage of quietness and simplicity, as compared with the gear or chain drive. The modern head-lamps, designed with a parabolic reflector and a focused filament, produce a beam which is slightly divergent. By means of prisms, some of the light is diverted on to the sides of the road and some in front of the car. The anti-dazzle problem has been partially solved, but the greatest problem of all has been, and it looks as if it always would be, driving in fog. The only alleviation seems to be to use a fog lamp which throws the light directly downwards on the road. This eliminates any rays in an upward direction which might be reflected back to the driver's eyes.

\section{Discoveries at Sakkara}

Discoveries of great interest and importance are announced from Sakkara, where excavations are being carried on by the Egyptian Department of Antiquities under the direction of Mr. Walter Emery and Zaki Effendi Saad. These discoveries were made in a tomb of the first dynasty, which was partially excavated in 1931 and then appeared to have been completely rifled. Further excavation in the present season, however, in a series of forty-two store chambers in the superstructure of the tomb which previously had escaped notice, has brought to light the complete grave furniture of Hamaka, the Vizier of Pharaoh Den of the first dynasty (c. 3,000 B.c.). At present about half these chambers have been cleared. They have yielded a large number of objects. Among them are numerous jars for containing wine, which bear seals giving the names of Hamaka and his king, implements, such as wooden sickles with flint teeth, the wooden handles of large adzes, and a number of large flint knives of advanced technique, of which some are more than a foot in length. A quiver contains reed arrows with tips of bone or flint, and a spear has a head of ivory, while an inscribed ebony tablet bears the name of the Pharaoh Zer. Remarkable as are some of these objects, such as the flint knives, in coming from a tomb, the discovery is given a unique character by a large number of disks of stone, bronze or ivory, for which the excavators are as yet not prepared even to conjecture the purpose. Some of the disks are inlaid with different varieties of stone, and one showing hounds chasing a gazelle is in a style which is said to remind the observer of the products of Minoan art of some fifteen hundred years later.

\section{Road Testing}

THE Department of Scientific and Industrial Research has just completed a road testing machine which is stated to be the Jargest of its kind in the world. According to The Times of April 8, road making and upkeep cost Great Britain about fifty million pounds a year, and thirty thousand pounds is being spent annually by the Department on research work on road engineering. The new testing machine consists of a 12-ton lorry, tethered to a central post by a 5 -ton structural arm driven by a 180 horse- 
power electric motor. It travels round a track 110 feet in diameter and wears two tracks on the test road. Its maximum speed is 40 miles an hour. Special safety devices have to be incorporated both in the design of the machine and of the building in which it is housed. If it broke away from the centre post when travelling at full speed, it would release energy equivalent to that of a six inch shell. The building containing the machine is roofed so that test roads may be laid in any weather. There are two other machines carrying out similar tests on a smaller scale. In the case of one of these machines the road revolves and drives the wheels, the maximum speed being nine miles per hour. A week's use of one of these machines sometimes represents a year's wear on the ordinary highway. It has been found out that the road generally wears out before the tyre gives way. Physical and chemical tests of roads and road making materials are also carried out at the laboratory. An appliance can bore out a cylindrical core of concrete from a road so that the texture and constituents of the mixture may be examined and its mechanical strength found. Tests on skidding are also made : theoretically, by a small apparatus in the laboratory which finds out the slipperiness of a lubricant, and practically, by means of a special motor cycle and sidecar.

\section{British Empire Cancer Campaign}

Ar the recent quarterly meeting of the Grand Council of the British Empire Cancer Campaign, a communication was received intimating that His Majesty the King had been graciously pleased to become patron of the Campaign. The following grants amounting to $£ 5,530$, and making a total to date of $£ 30,990$ for the year 1936, were approved: $£ 1,100$ to the Radium Beam Therapy Research ; $\mathfrak{1 1 , 7 5 0}$ (in addition to the grant of $\mathfrak{1} 1,850$ already made for the year 1936) to the Mount Vernon Hospital; $£ 500$ (in addition to the grant of $£ 600$ already made for the year 1936) to the Marie Curie Hospital ; $£ 100$ and $£ 80$ to Dr. C. R. Amies, at the Lister Institute and Dr. P. R. Peacock, of Glasgow, respectively, for the

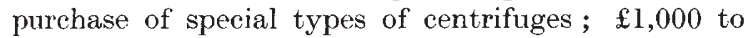
the Manchester Committee on Cancer to cover the cost for two years of investigations to ascertain whether there is any connexion between the use of heary oils in motor-vehicles and the apparent increase in the incidence of cancer of the upper air passages and the lung; $£ 1,000$ to the North of England Branch of the Campaign to meet the cost for the second year of the short-wave investigations being carried out at Newcastle, on behalf of the Campaign, under the direction of Prof. W. E. Curtis and Dr. F. Dickens. In this connexion the Council expressed its appreciation of the technical assistance afforded the workers by the technical staff of the Marconi Company. The Royal Society and the Medical Research Council have nominated Prof. Matthew Stewart, of the University of Leeds, to succeed Prof. R. T. Leiper, who has retired, as one of their five nominees on the Scientific Advisory Committee of the Campaign.

\section{A New Hydraulic Laboratory}

HydRAUlic laboratories are in use for a variety of purposes, including the training of engineers, tests of turbines and pumps, model experiments on ships and seaplane floats and for research on river, reclamation and harbour problems. In the Engineer of April 3, Dr. F. V. A. E. Engel reviews some of the aspects in the design of such laboratories and gives a detailed description of the new hydraulic laboratory at the Park Royal works of Messrs. Electroflo Meters Co. Ltd., erected for the routine work of testing and calibrating meters and for the development and improvement of fluid flow measuring devices. A factor of importance in the design of a meter test plant, he says, is the maintenance of a constant head in the test line. In the plant at the Park Royal works, water is drawn from a sump by two electrically driven centrifugal pumps and delivered to an overhead tank 65 feet above the ground floor. The water then flows through the test line, where Venturi tubes and orifice plates may be installed in a straight pipe $60 \mathrm{ft}$. long. From the test line the water passes into a settling tank and two measuring tanks, and so back to the sump. For timing the tests an interesting device has been adopted which automatically operates the stop watch. When the flow of water entering one measuring tank is switched over to the other, the water jet from the change-over valve interrupts a beam of light impinging on a photo-electric cell, and by means of a thermionic amplifier and relay the stop watch is controlled. In the new laboratory, investigations are in progress on a model of a large Venturi flume recently constructed at the West Middlesex sewerage works at Mogden.

\section{Botanical Acquisitions at the Natural History Museum}

CAPT. F. KINGDON-WARD has presented more than 1,100 specimens collected on his recent expedition to Tibet to the Department of Botany of the British Museum (Natural History). Mr. R. F. Jones has made a collection of plants during the Percy Sladen Expedition to Lake Hula. The lake and its adjacent swamp, an area of about seventeen square miles, was concentrated upon, as the flora will disappear with drainage, and the flora of the hills of Palestine is fairly well known. The collection is of more than four hundred numbers and includes all groups. The investigation was mainly ecological, but the collection contains several new records of flowering plants. Lieut.-Colonel F. M. Bailey, British Envoy Extraordinary and Minister Plenipotentiary at Katmandu, Nepal, has presented 488 flowering plants and 42 vascular cryptogams. These make a useful addition to the valuable Nepalese collections already in tho Department.

\section{Indian Helminths}

G. D. BHALERAO has prepared a list of the helminth parasites hitherto recorded from domesticated animals in India (Imperial Council of Agricultural Research. Scientific Monograph No. 6. Pp. 365. Delhi, 1935. 13s. 3d.). A brief account of the technique of collecting, preserving and preparing the parasites for 